\title{
An adjuvanted subunit SARS-CoV-2 spike protein vaccine provides protection against Covid-19 infection and transmission
}

\section{Kairat Tabynov}

Kazakh National Agrarian Research University

\section{Nurkeldi Turebekov}

M. Aikimbayev's National Research Center for Especially Dangerous Infections https://orcid.org/00000001-6826-2611

\section{Meruert Babayeva}

Kazakh National Agrarian Research University

\section{Gleb Fomin}

Kazakh National Agrarian Research University

\section{Toktasyn Yerubaev}

M. Aikimbayev National Research Center for Especially Dangerous Infections

\section{Tlektes Yespolov}

Kazakh National Agrarian Research University

\section{Lei Li}

Vaxine Pty Ltd

\section{Gourapura Renukaradhya}

Ohio State University

\section{Nikolai Petrovsky}

Finders University https://orcid.org/0000-0002-1580-5245

Kaissar Tabynov ( $\nabla$ tabynov_81@mail.ru )

Kazakh National Agrarian Research University

\section{Article}

Keywords: SARS-CoV-2, Subunit vaccine, Spike protein, Receptor-binding domain, Antibody and cellular immune responses, Protective efficacy, Transmission, Delta variant virus, Mice and hamsters

Posted Date: September 21st, 2021

DOI: https://doi.org/10.21203/rs.3.rs-902649/v1 
License: (c) (i) This work is licensed under a Creative Commons Attribution 4.0 International License. Read Full License

Version of Record: A version of this preprint was published at npj Vaccines on February 23rd, 2022. See the published version at https://doi.org/10.1038/s41541-022-00450-8. 
1 An adjuvanted subunit SARS-CoV-2 spike protein vaccine provides protection against

2 Covid-19 infection and transmission

3

4 Kairat Tabynov ${ }^{1}$, Nurkeldy Turebekov ${ }^{2}$, Meruert Babayeva $^{1}$, Gleb Fomin ${ }^{1}$, Toktasyn Yerubaev ${ }^{2}$,

5 Tlektes Yespolov ${ }^{1}$, Lei Li $^{3}$, Gourapura J Renukaradhya ${ }^{4}$, Nikolai Petrovsky ${ }^{3}$, Kaissar Tabynov ${ }^{1 *}$

6

$7 \quad{ }^{1}$ International Center for Vaccinology, Kazakh National Agrarian Research University

8 (KazNARU), Almaty, Kazakhstan

$9 \quad{ }^{2}$ Preclinical Research Laboratory with Vivarium, M. Aikimbayev National Research Center for

10 Especially Dangerous Infections, Almaty, Kazakhstan

$11 \quad{ }^{3}$ Vaxine Pty Ltd and Flinders University, Bedford Park, Australia

$12{ }^{4}$ Center for Food Animal Health, Ohio Agricultural Research and Development Center, The

13 Ohio State University (OSU), Wooster, OH 44691, United States.

14

$15 *$ Corresponding author

16 E-mail: tabynov81@mail.ru, kaissar.tabynov@kaznau.kz 


\section{Abstract}

18

Recombinant protein approaches offer major promise for safe and effective vaccine prevention of SARS-CoV-2 infection. We developed a recombinant spike protein vaccine (called NARUVAX-C19) and characterized its ability when formulated with a nanoemulsion adjuvant to induce anti-spike antibody and T-cell responses and provide protection including against viral transmission in rodent. In mice, NARUVAX-C19 vaccine administered intramuscularly twice at 21-day interval elicited balanced Th1/Th2 humoral and T-cell responses with high titers of neutralizing antibodies against wild-type (D614G) and delta (B.1.617.2) variants. In Syrian hamsters, NARUVAX-C19 provided complete protection against wild-type (D614G) infection and prevented its transmission to naïve animals placed in the same cage as challenged animals. The results contrasted with only weak protection seen with a monomeric spike receptor binding domain (RBD) vaccine even when formulated with the same adjuvant. These encouraging results warrant ongoing development of this Covid-19 vaccine candidate.

Keywords: SARS-CoV-2; Subunit vaccine; Spike protein; Receptor-binding domain; Antibody and cellular immune responses; Protective efficacy; Transmission; Delta variant virus; Mice and hamsters 
Currently, the world remains in the epicenter of a coronavirus pandemic caused by Severe Acute

Respiratory Syndrome Coronavirus - 2 (SARS-CoV-2). This pandemic has affected every country in the world, and as of August 2021, confirmed cases totaled over 200 million, with at least 4.2 million deaths [1]. New variants continue to emerge, making containment strategies difficult [1], due to immune escape [2,3]. Countries with high vaccination coverage have seen reduced hospitalizations and deaths as a percentage of infection cases [1], supporting the role of vaccines in reducing the severity and health impacts of COVID-19 infection. Much weaker evidence is available on the role of current vaccines in reducing virus transmission in the even in countries with high vaccination coverage.

Several vaccines (inactivated-, mRNA-, and vector-based) are already available for use under emergency authorization [4], but are currently insufficient to meet global demand. So far with over 4 billion doses of vaccine distributed, just $14.9 \%$ of the world's population has been fully vaccinated, with only $1.1 \%$ of people in low-income countries having received at least one dose [5]. The development of additional vaccines with different mechanisms of action could help in mitigating the global impact of SARS-CoV-2, with a major missing link being the ongoing lack of availability of traditional recombinant protein subunit vaccines. Protein-based vaccines have advantages over other technologies with a 40-year record of high safety and efficacy including in young infants, plus low cost of goods, reliable large-scale production and stability under normal refrigeration conditions [6].

We developed a subunit COVID-19 vaccine (called NARUVAX-C19) based on recombinant spike protein extracellular domain expressed in insect cells that was then formulated with Sepivac SWETM, a nanoemulsion oil (SWE) adjuvant. In this study, we evaluated the antibody and T-cell responses and protective efficacy of the NARUVAX-C19 vaccine including against 
60 virus transmission. For comparison, vaccines based on monomeric RBD protein formulated with

61 oil adjuvants were also included. This is one of the first studies to directly compare spike protein

62 with RBD antigens and to evaluate the ability of such vaccines to block viral transmission to

63 naive animals. As shown, NARUVAX-C19 vaccine induced potent humoral and cellular

64 immune responses, protected hamsters against viral challenge and prevented virus transmission

65 from challenged to naïve animals

\section{Results}

\section{$67 \quad 1.1$ Antibody response in vaccinated mice}

68 In mice, both spike and RBD proteins formulated with SWE adjuvant induced serum antigenspecific IgG 21 days after a single immunization (Figure 1A) that were further boosted after the second immunization (Figure 1B), with significantly higher IgG in groups that received adjuvanted versus unadjuvanted RBD and spike proteins. Notably, anti-spike or RBD IgG was only seen after two doses of unadjuvanted antigen. Both IgG1 and IgG2 subtypes were produced against spike or RBD protein. At 21 days after booster vaccination (Figure 1B), the difference between IgG1 and IgG2a antibody titers in all the vaccinated groups was not significant. Suggesting there was a switch of immune response from Th-2 polarized to a balanced Th1 and Th2 response. This was not the case for the antigens itself, where the difference between IgG1 isotype antibody titers over IgG2a remained significant during the indicated observant. 
(A)
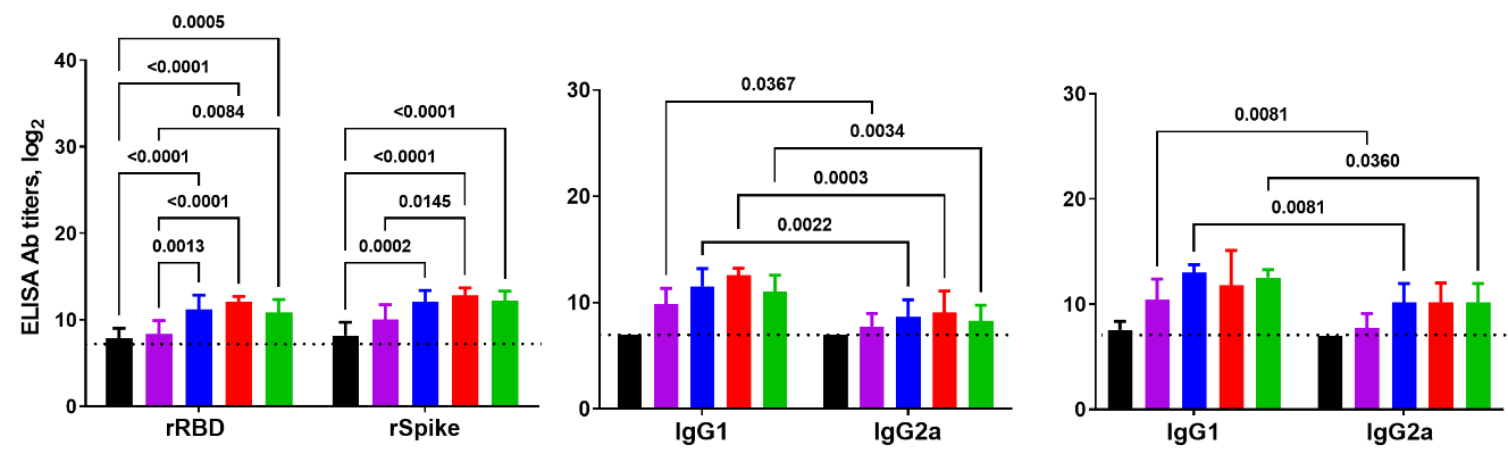

(B)

$\lg \mathbf{G}$

rRBD

rSpike
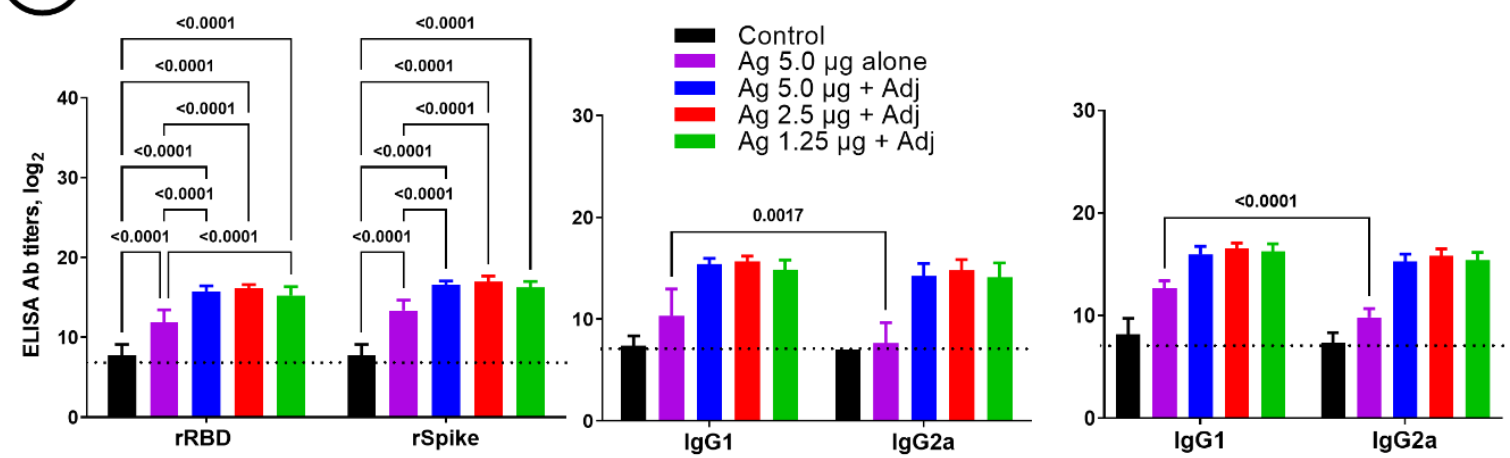

Figure 1: Specific IgG, IgG1 and IgG2a titers in serum of BALB/c mice vaccinated with RBD or Spike protein antigens 21 days after prime (A) and booster (B) immunization. Antigens were used at doses of 1.25 , 2.5 , and $5 \mu \mathrm{g}$ with SWE adjuvant. For comparison, $5 \mu \mathrm{g}$ vaccine was given without adjuvant and a negative control vaccine comprised SWE adjuvant with no antigen. Antibody levels are presented as geometric mean titers (GMT) with a 95\% confidence interval. Differences in IgG titers were assessed using Tukey's multiple comparisons test. A $\mathrm{P}<0.05$ value was considered as a significant difference.

We next determined the ability of immune sera to block the binding of SARS-CoV-2 RBD

protein to the ACE2 receptor. The SWE adjuvanted spike protein vaccine generated RBD-ACE2

blocking antibodies in $57.1-71.4 \%$ of mice at tested doses as early as 21 days after a single immunization, which was significantly higher than that of the RBD-based vaccine $(0-42.8 \%)$ (Figure 2A) with RBD-ACE2 blocking antibodies not seen in animals immunised with unadjuvanted RBD or Spike antigens alone. At 21 days after the booster immunization, the percentage of mice with RBD-ACE2 blocking antibodies in all groups reached 100\% (Figure 2B). Overall, the spike protein immunized groups demonstrated higher RBD-ACE2 blocking antibody levels over the RBD immunized groups. 
At 21 days after prime immunization, neutralizing antibodies against the wild-type SARS-CoV-2 virus were detected in some animals in the SWE adjuvanted Spike protein vaccine groups

(Figure 2C) and just one animal in the adjuvanted RBD $(2.5 \mu \mathrm{g})$ group. After booster immunization (Figure 2D), the adjuvanted spike protein groups at all three doses had high neutralizing antibodies titers (GMT 475-706), which were significantly higher than the antigen alone group (GMT 11-20), the controls, and the corresponding groups immunized with RBD antigen (GMT 20-40).
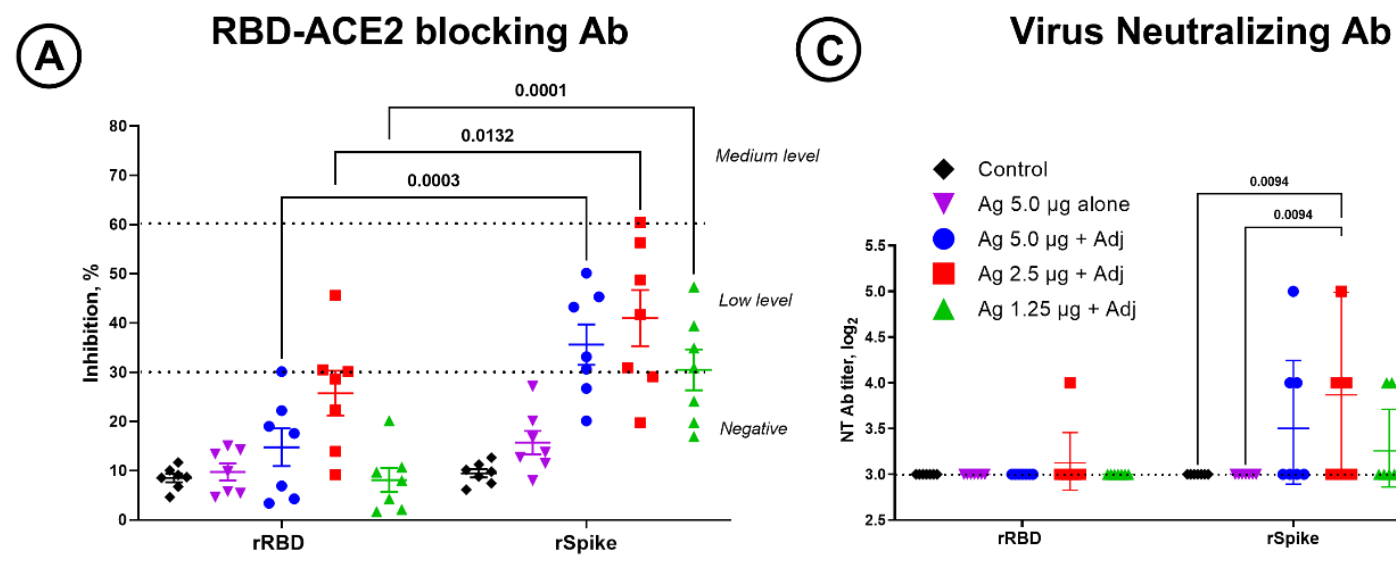

(B) RBD-ACE2 blocking Ab
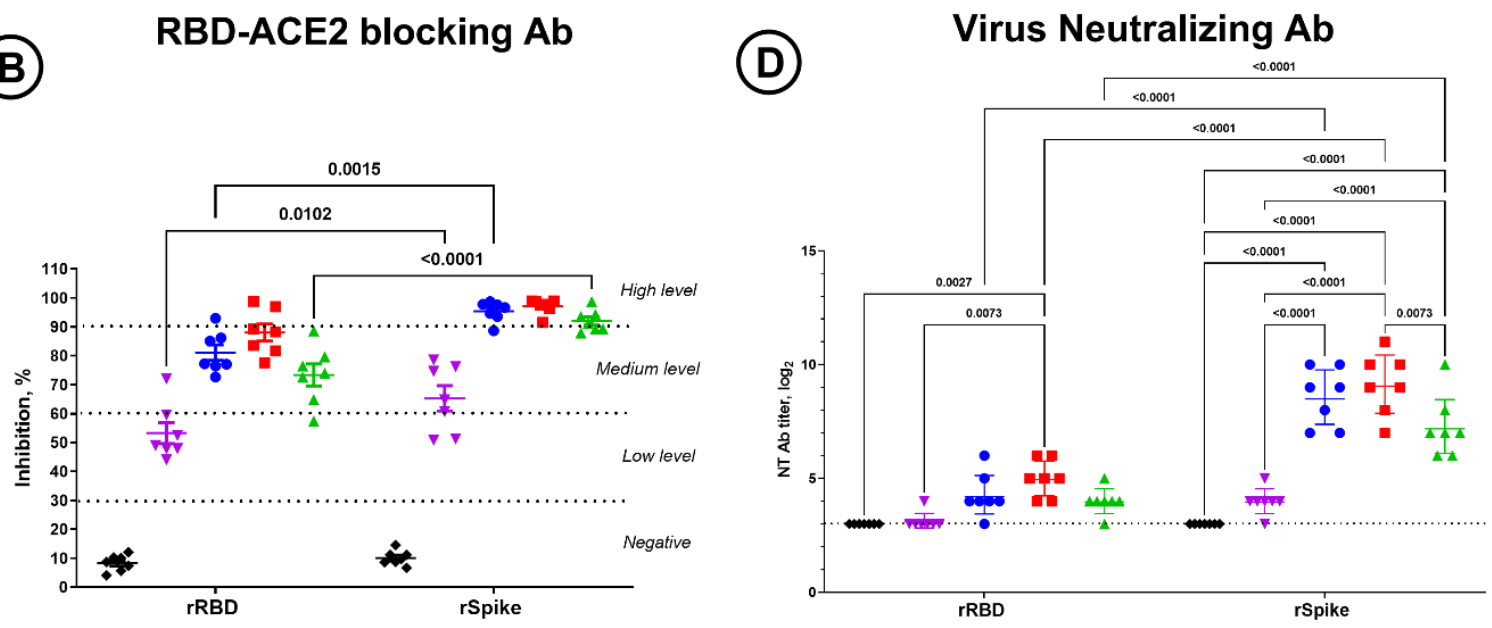

103

104

Figure 2: RBD-ACE2 blocking and virus neutralizing antibody titers in BALB/c mice at 21 days after prime (A, C) and booster (B, D) immunization with RBD and Spike protein vaccines. Vaccines were formulated with SWE adjuvant. Controls included vaccine without adjuvant containing RBD or Spike antigen at a dose of $5.0 \mu \mathrm{g}$ $(\mathrm{Ag} 5.0 \mu \mathrm{g})$ and an adjuvant-alone group. RBD-ACE2 blocking antibodies were determined according to the level of inhibition: negative $(<30 \%)$, low $(30-59 \%)$, medium $(60-89)$, and high $(90 \leq)$. Viral neutralizing antibody levels are presented as geometric mean titers (GMT) with a $95 \%$ confidence interval. Differences in antibody titers between groups were assessed using Tukey's multiple comparisons test. 
Evaluation of cytokine production in response to restimulation of mouse splenocytes with the corresponding proteins (RBD or Spike) showed that after two immunizations both the SWE adjuvanted RBD and Spike vaccines induced robust cellular immune responses (Figure 3A). Adjuvanted RBD and Spike-based vaccines induced significantly higher production of both Th1 (IFN-gamma, IL-2, TNF- $\alpha$, IL-17A) and Th2 (IL-4, IL-5, IL-6, IL-9, IL-10) cytokines compared to antigen alone groups and control groups. Production of cytokines like IL-2, TNF- $\alpha$ and IL-10 was higher $(P=0.0077-<0.0001)$ in the spike-based adjuvanted vaccine group (predominantly at a dose of $2.5 \mu \mathrm{g}$ ) compared to that of the RBD antigen-based vaccine. Hence, two doses of SWE adjuvanted Spike or RBD antigen successfully induced Th1 and Th2 memory T cell responses.

Similar patterns were observed in the antigen-stimulated CD4+ and CD8+ T cell proliferation responses (Figure 3B). Again, SWE adjuvanted RBD and Spike antigens induced significantly higher CD4+ T cell proliferation when stimulated with the corresponding proteins. The CD8+ cell proliferation for adjuvanted RBD and Spike antigens trended higher than those of the did not achieve statistical significance.
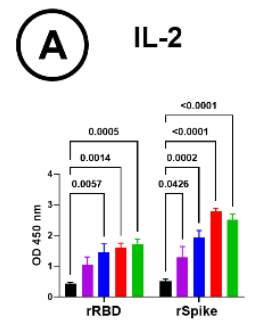

IL-4

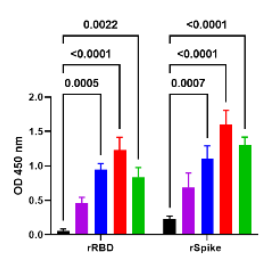

IFN-Y

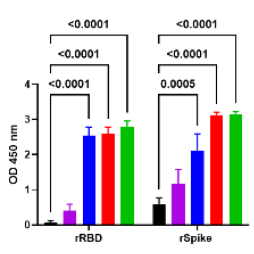

IL-5

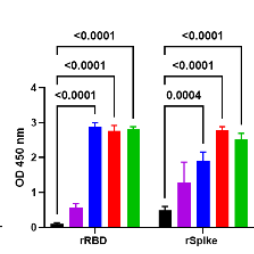

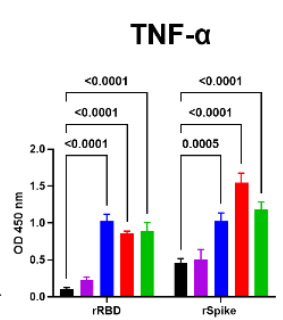

IL-6

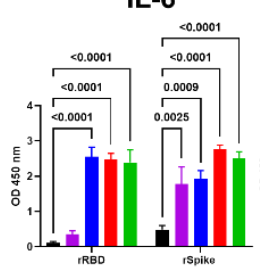

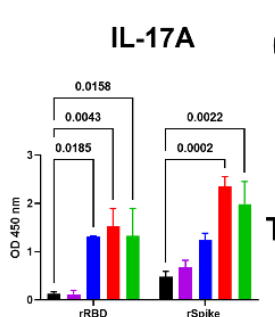

IL-10

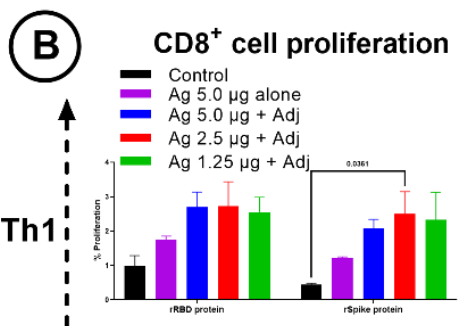

$\mathrm{CD}^{+}$cell proliferation

Figure 3: Cytokine production (A) and CD4+ and CD8+ T cell proliferation (B) in splenocytes from RBD and Spike vaccinated BALB/c mice. Cytokine data were presented as the difference (delta) in OD between samples with or without protein stimulation. CD4+ and CD8+ T cell proliferation was calculated as the difference $(\Delta)$ in 
number of proliferating (CFSE+) splenocytes between stimulated vs non-stimulated cells. Statistical differences were assessed using Śídák's multiple comparisons test. A $\mathrm{P}<0.05$ value was considered as a significant difference.

\subsection{Vaccine immunogenicity in hamsters}

Immunogenicity in hamsters of our vaccine candidates were evaluated at day 21 after a booster intramuscular immunization. Unlike the mouse experiment, only a single vaccine dose of 5.0 $\mu \mathrm{g} /$ animal was used and no antigen-only groups were included, as in the mouse studies antigen alone did not induce neutralizing antibodies or a strong $\mathrm{T}$ cell response. Responses in vaccinated animals were compared to serum samples collected 21 days post infection of hamsters with wildtype D614G SARS-CoV-2 virus (WT convalescent sera).

In the hamsters, SWE-adjuvanted Spike vaccine again induced significantly higher anti-spike IgG titers (GMT 35,918) than SWE-adjuvanted RBD vaccine (GMT 14,254) vaccine (Figure 4A). Anti-spike IgG levels in SWE-adjuvanted Spike vaccine equaled or exceeded levels seen in convalescent sera.

All animals that received SWE-adjuvanted Spike vaccine had either high (4/6) or medium (2/6) levels of RBD-ACE2 blocking antibodies, which equaled levels in WT convalescent sera (Figure 4B). By contrast, SWE-adjuvanted RBD vaccine induced RBD-ACE2 blocking antibody at low to medium levels in only $50 \%$ of animals.

Next, sera were assessed for neutralizing activity against wild-type D614G or the delta variant of SARS-CoV-2 virus. Consistent with the high levels of specific IgG and RBD-ACE2 blocking antibodies in the SWE-adjuvanted Spike immunised animals, this group also exhibited the highest titers of neutralizing antibodies (GMT 320), equivalent to levels seen in WT convalescent sera (GMT 160). These levels were significantly higher than for SWE-adjuvanted RBD vaccine (GMT 17.8).

Cross-neutralizing responses against the SARS-CoV-2 delta variant were measurable in $100 \%$ of animals that received SWE-adjuvanted Spike (GMT 89.8) with levels comparable to WT 
convalescent sera (GMT 67.2), whereas they were undetectable in the majority of animals that received SWE-adjuvanted RBD vaccine. Overall, neutralizing activity against the Delta variant was $\sim 3$ fold lower than against the wild-type virus in the SWE-adjuvanted Spike vaccinated animals with the same trend apparent in WT convalescent sera (Figure 4D).

(A)

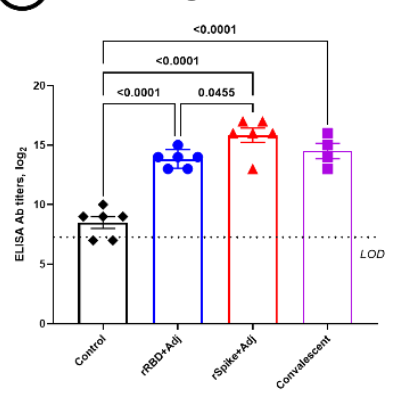

(B) RBD-ACE2 blocking Ab

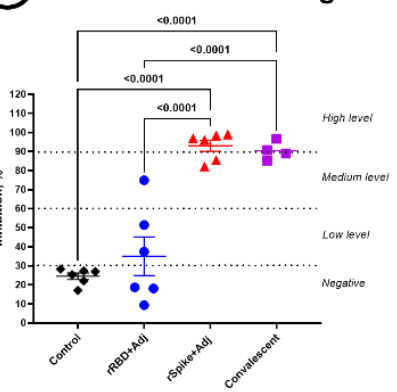

(C) NT Ab (Wild-type D614G)

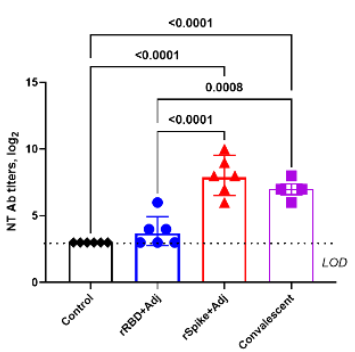

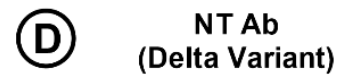

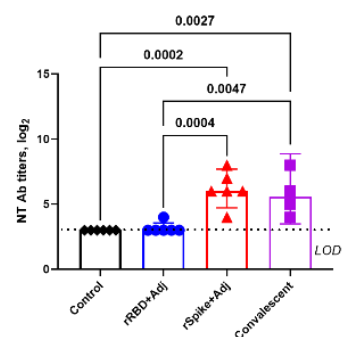

Figure 4: Spike-specific IgG (A), RBD-ACE2 blocking antibody (B) and neutralizing antibody (C, D) levels in hamsters 21 days after booster immunization as compared to levels in WT convalescent sera. Viral neutralizing antibodies were assessed against wildtype D614G (C) and delta variant (D) viruses. Differences between groups assessed using Dunnett's multiple comparisons test.

\subsection{Assessment of vaccine efficacy}

\section{Weight changes}

On day 21 after booster injection, immunized and control hamsters were intranasally challenged with $1 \times 10^{4}$ TCID $_{50}$ WT SARS-CoV-2 virus. Weights were monitored daily for 7 days after challenge infection (Figure 5A). Only animals vaccinated with SWE-adjuvanted Spike vaccine showed an increase in body weight gain during the period of observation, with all other groups losing weight. In animals that received SWE-adjuvanted RBD vaccine, body weight stayed stable on day $2-3$, but from day 4 there was a reduction, which reached a maximum $(1.77 \%$ loss $)$ on day 7. In the control group, there was a steady decline in body weight reaching $9.8 \%$ reduction on day 7 . There was a significant difference in animal weight between the Spike-based vaccine and the control group on days 4-7 after challenge infection, and the RBD-based vaccine and the control group on day 7 post challenge. In addition to weight loss, some of control 
animals showed clinical signs of infection with depressed activity and disheveled appearance, but similar signs were not seen in the vaccinated animals.

\section{Viral load in the respiratory tract}

Viral load was determined in suspensions of nasal turbinates and lungs on days 3 and 7 after challenge infection by real-time PCR (expressed in cycles/Ct) and by culture of infectious virus $\left(\log _{10} \mathrm{TCID}_{50} / 0.2 \mathrm{~mL}\right)$. PCR was positive for viral RNA in nasal turbinates and lungs on day 3 after challenge in all groups (Figure 5B \& C). However, on day 7 after challenge there was a complete absence of viral RNA (negative sample Ct of over 40) in nasal turbinates and lungs only in the group that received SWE-adjuvanted Spike vaccine (Figure 5C). As detection of viral RNA by PCR early after challenge may just reflect the residual challenge virus, a more specific test for active infection is to measure culturable virus. Notably, animals vaccinated with SWEadjuvanted Spike vaccine had undetectable infectious virus in oropharyngeal swabs taken on Day 2 or nasal turbinate or lung samples on days 3 and 7 post challenge (Figure 5E, F, G). By contrast, on infectious virus was detectable in Day 2 oropharyngeal swabs and day 3 nasal turbinate and lung samples in all control animals as well as animals vaccinated with SWEadjuvanted RBD vaccine although infectious virus levels in the latter were significantly lower than in the control group. On day 7 after challenge, infectious virus was still detectable at low levels in nasal turbinate and lung samples of $2 / 3$ animals in the control group but none of the vaccinated animals.

\section{Protection against virus transmission}

To test for an effect of vaccination on ability of a challenged animal to transmit virus, two naive sentinel animals were introduced into each cage containing infected animals on the $2^{\text {nd }}$ day after 
challenge infection (Day 2). Two sentinels was left in contact with the infected animals for just one day and then removed and housed alone for a further 4 days before sacrifice whereas. On day 7 post challenge, all infected and sentinel animals were euthanized and viral load assessed in the nasal turbinates and lungs. Notably, only animals immunized with SWE-adjuvanted Spike vaccine did not transmit infection to the contact sentinel animals, as indicated by absence in their nasal turbinates or lung samples of viral RNA by PCR (Figure 5D), infectious virus by culture (Figure 5H), and these sentinel animals showing positive weight gain of 5-6\% from prior to being placed in the infected cage to the end of the study period (data not shown). By contrast, sentinels demonstrated evidence of active virus transmission after being placed in the infected control group cage, with virus detected by PCR and virus culture at high titers in their nasal turbinates $(3.62 \pm 1.12)$ and lungs $\left(1.5 \pm 1.0 \log _{10} \mathrm{TCID}_{50} / 0.2 \mathrm{~mL}\right)$ and the sentinels demonstrating a $3.5-4.8 \%$ body weight decrease consistent with active infection (data not shown). The sentinels placed in the SWE-adjuvanted RBD vaccine group also showed evidence of virus transmission, with virus detectable in their nasal turbinates by both PCR and virus culture.

\section{Lung histology}

Next lung histology was assessed in infected animals to assess the extent of clinical disease.

With the exception of the SWE-adjuvanted Spike vaccine group, the lungs of all infected hamsters showed classic histological signs of acute respiratory distress syndrome (ARDS) caused by SARS-CoV-2 infection. Morphological characterization of the lungs in the SWEadjuvanted RBD vaccine and control groups demonstrated signs of the exudative phase of ARDS day 3 post-infection and fibroproliferative phase on day 7 post-infection (Figure 5J). Similar lung pathology was seen in the sentinel animals placed in contact with the infected SWEadjuvanted RBD vaccine and control groups. Scoring of lung pathology, confirmed the highest pathology scores in the control animals followed by the SWE-adjuvanted RBD vaccine group 


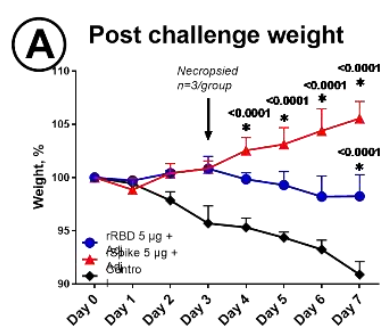

(E) Virus titer day 2

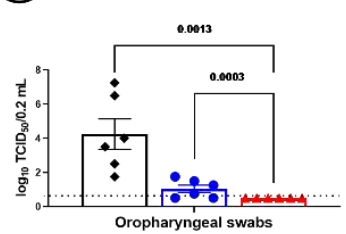

(1)

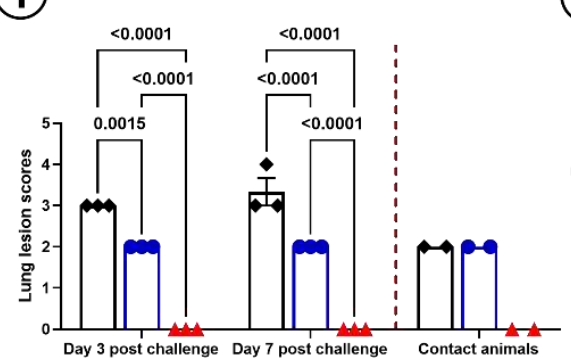

Day 3

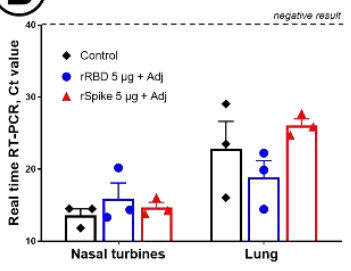

(F) Virus titer day 3
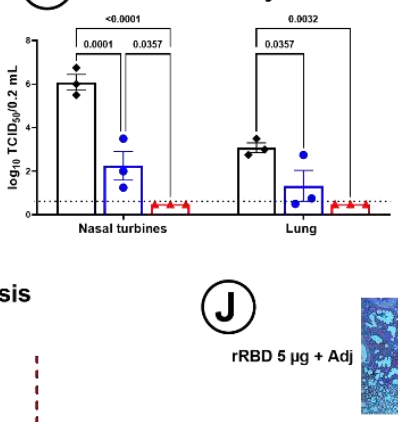

Day 3

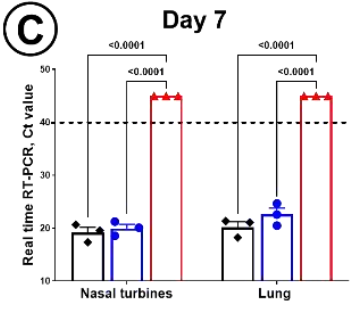

G) Virus titer day 7
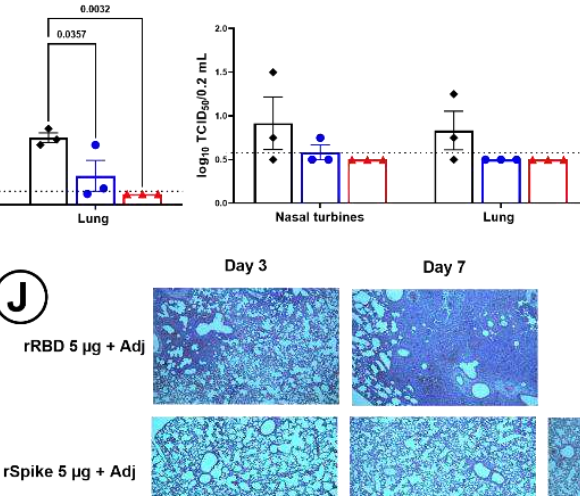

rSpike $5 \mu \mathrm{\mu g}$ Adj

Control

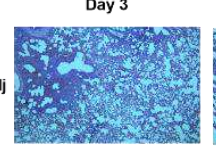

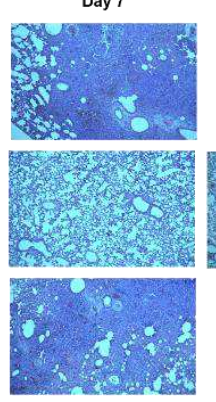

Day 7
(D) Contact animals

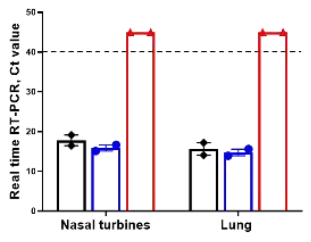

(H)

Contact animals
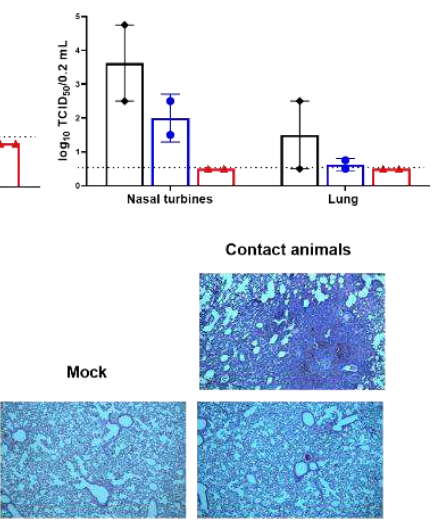

Figure 5: Vaccine protection in Syrian hamsters against SARS-CoV-2 infection and virus transmission. To

Next, to identify the best correlate of protection, we evaluated the correlation between immune parameters then measured: 1 ) changes in body weight $(\mathbf{A} ; n=3$-6/group); virus excretion from oropharyngeal swabs day 2 post challenge ( $\mathbf{E} ; \mathrm{n}=6$ /group) 2) viral load in nasal turbinates (n=3/group) and lungs (n=3/group) by PCR (represented by $\mathrm{Ct} ; \mathrm{B}, \mathrm{C}$ ) and culture of infectious virus (expressed as $\left.\log _{10} \mathrm{TCID}_{50} / 0.2 \mathrm{~mL} ; \mathbf{F}, \mathbf{G}\right) ; 3$ ) histopathological changes in the lungs ( $\mathbf{I}, \mathbf{J}$ ), on days 3 ( $n=3$ /group) and 7 (n=3/group) after challenge infection. Efficacy against virus transmission in contact sentinel animals ( $n=2 /$ group) was evaluated by detection of viral load $(\mathbf{D}, \mathbf{H})$, lung pathology scoring $(\mathbf{I}, \mathbf{J})$. Differences in the studied parameters between animal groups were assessed using Tukey's, Dunnett's, or Š́dák's multiple comparisons test. A $\mathrm{P}<0.05$ value was considered as a significant difference. * in comparison with the control group.

markers including various antibody measurements and measures of vaccine protection including weight changes, viral loads, and lung pathology (Figure 6). The was a strong correlation between weight loss and lung pathology scores $(\mathrm{r}=0.70, P=0.001)$, suggesting weight changes are a useful 
non-invasive measure for assessing disease severity. Notably, the strongest correlate of protection was found between pre-challenge levels of anti-spike IgG, RBD-ACE2 binding inhibition and WT SARS-CoV-2 neutralizing antibodies and lung pathology scores, consistent with serum antibody levels post-vaccination being the best predictor of lung protection from infection.

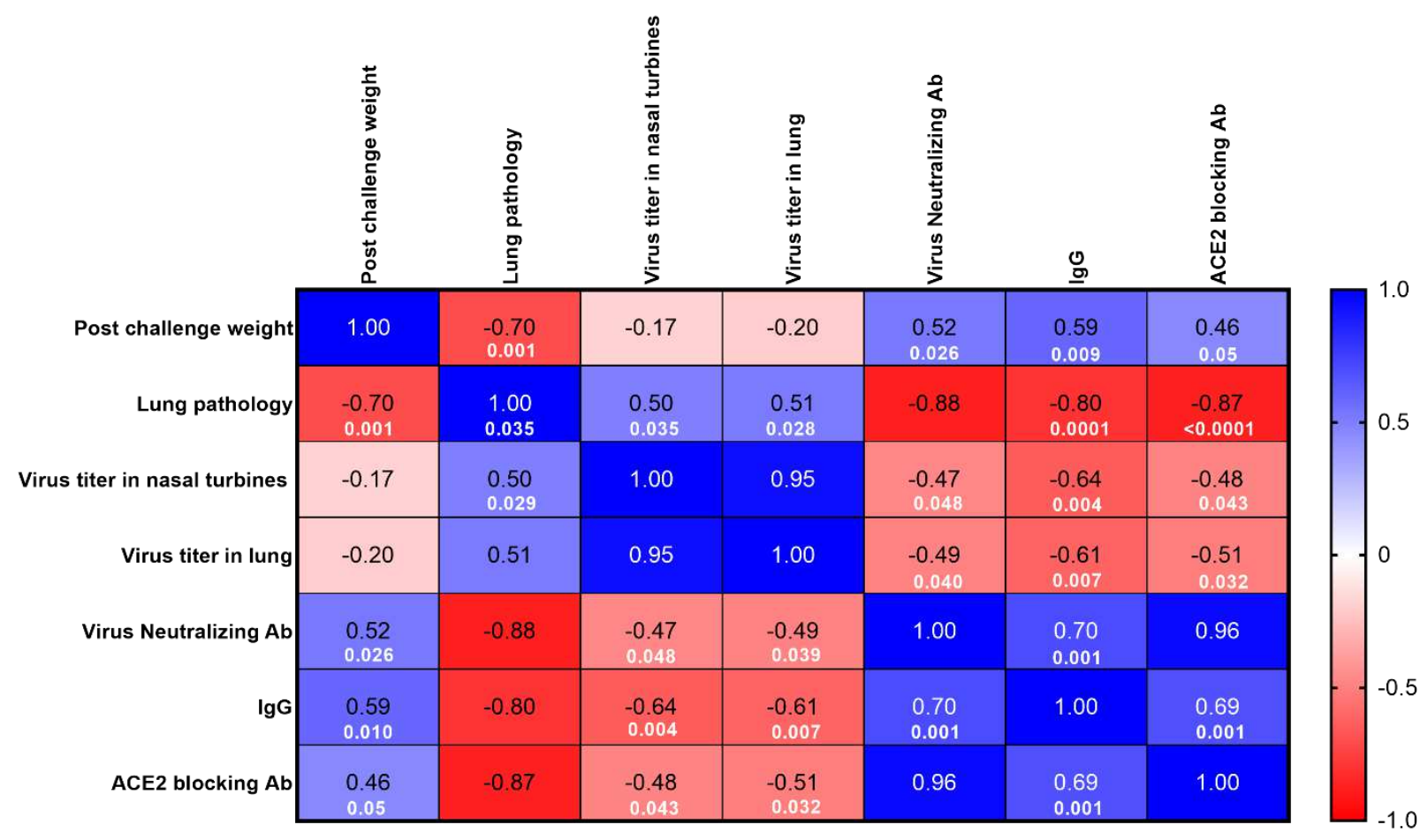

Figure 6: Correlation matrix analysis between immune markers including various antibody measurements and measures of vaccine protection including weight changes, viral loads, and lung pathology. The color refers to $r$ value scale ( -1 to 1$)$ shown on the right. The number in each cell indicates the actual $r$ value and the stars represent $p$-values. The analysis was conducted by multivariable Pearson correlation method.

\section{Discussion}

Subunit vaccines are well-established as a reliable and safe platform effective against a variety of infectious diseases such as hepatitis B, diphtheria, pertussis, shingles and human papillomavirus [7]. Development of a subunit vaccine against SARS-CoV-2 would represent an important step 
in the fight against the COVID-19 pandemic. Among the 110 COVID-19 vaccine candidates in clinical trials, the largest number 37 (34\%), are subunit preparations [4]. Approximately half (16/37) of these candidates use full-length Spike protein, with the rest focused on just spike RBD or peptides [4]. Our research group consisting of a consortium of academic institutions such as the International Center for Vaccinology at the Kazakh National Agrarian Research University (KazNARU) and the Aikimbayev National Research Center for Especially Dangerous Infections of the Ministry of Health of the Republic of Kazakhstan has been developing a protein subunit vaccine against COVID-19 called NARUVAX-C19 in collaboration with Australian biotechnology company Vaxine Pty Ltd. The vaccine is prepared from the extracellular domain of Spike protein derived from baculovirus expression in insect cells with an amino acid sequence corresponding to wild-type SARS-CoV-2 (Wuhan strain) together with some stabilizing mutations. This Spike ECD protein has been previously characterized in mice and ferrets as part of a vaccine called COVAX-19/SpikoGen [8] that has already entered phase III clinical trials in the Middle East [4]. Adjuvants are generally needed to increase the effectiveness of subunit vaccines [9]. In the current studies we combined this Spike ECD protein with a squalenecontaining oil-water emulsion type adjuvant SWE (Seppic, France), which is analogous to MF59, another well-known emulsion adjuvant (Sequiris, USA). SWE is also being used as part of a subunit vaccine from the University of Saskatchewan which is in Phase I/II trials [4].

We compared NARUVAX-C19 to another vaccine based on recombinant monomeric spike RBD protein, a popular target for COVID-19 vaccine development. Spike RBD is responsible for SARS-CoV-2 binding to the ACE-2 receptor for cell entry [10] and RBD protein has been favored by some vaccine researchers because of its small size and easy expression at high concentrations in various expression systems [11]. However, RBD has fewer B and T cell epitopes than full-length Spike protein [12] an although much neutralizing antibody is directed at the RBD, it is now recognized that neutralizing antibodies are also directed at other regions of 
the Spike protein including the N-terminal domain and the fusion peptide, epitopes not present in RBD vaccines.

In the mouse model, we showed the potential of SWE-adjuvanted RBD and Spike vaccines to elicit humoral and T-cell immune responses with SWE-adjuvanted Spike vaccine inducing the highest levels of spike-binding IgG (IgG1 and IgG2a), RBD-ACE2 blocking antibodies and WT and variant delta SARS-CoV-2 neutralizing antibodies after both prime and booster immunizations. By comparison, even when formulated with the same SWE adjuvant, the RBD vaccine even after two immunization failed to induce significant titers of virus neutralizing antibodies in mice. The low immunogenicity of RBD antigen is consistent with data from a phase I trial of a recombinant tandem-repeat dimeric RBD vaccine (ZF2001) which required 3 doses of $25 \mu \mathrm{g}$ of the RBD antigen to ensure seroconversion of neutralizing antibodies in $97 \%$ of participants [13].

The ideal SARS-CoV-2 vaccine should also elicit a strong cellular response [14], with Th1 cellular immunity being shown to contribute to SARS-CoV-2 protection [15]. In our study, SWE-adjuvanted Spike vaccine again induced the strongest cellular immune response, as indicated by antigen-stimulated cytokine production and CD4+ and CD8+ T cell proliferation, with higher IL-2 and TNF than the RBD vaccine, consistent with more Th1 bias.

Finally, we assessed the two vaccines for immunogenicity and protective efficacy in the Syrian hamster model, one of the most sensitive models for SARS-CoV-2 infection [16]. In hamsters, the RBD vaccine was again confirmed as a weak antigen inducing only low levels antigenspecific IgG and RBD-ACE2 blocking antibodies, and neutralizing antibody titers and this translated into only modest protection in response to challenge with heterologous D614G mutant SARS-CoV-2 [17], with weight loss and detectable virus in day 2 nasopharyngeal swabs and day 3 nasal bulb and lung tissue. By contrast, the SWE-adjuvanted Spike vaccine induced high levels of spike-binding IgG, RBD-ACE2 blocking antibodies and neutralizing antibody including 
against the delta variant that were similar in level to those of convalescent infected hamsters.

319 This translated into robust protection against SARS-CoV-2 infection with the animals gaining rather than losing weight after challenge, and having no recoverable virus in day 2 oropharyngeal swabs as well as day 3 nasal bulb and lung samples. Notably, only the animals immunized with SWE-adjuvanted Spike vaccine were unable to transmit infection to naïve sentinel mice placed into their cages day 2 after challenge.

Notably, in other published studies in hamsters or humanized mice of immunization with the widely used adenoviral vector $[18,19]$ or mRNA [20] vaccines showed these animals still had infectious virus recoverable from their upper respiratory tract after infection. Similarly, nonhuman primates immunized with the AstraZeneca adenoviral vector showed equal amounts of virus in the nasal bulb post-challenge as unvaccinated animals [21]. Further, a recombinant spike protein vaccine based on a HIV-trimerisation domain and formulated with MF59 adjuvant, while showing reduced lung virus titers, had minimal effects on nasal virus replication when compared to unvaccinated controls [22]. Hence these other Covid-19 vaccines largely appear to mediate 
Lastly, there is an ongoing search for strong correlates of vaccine protection, that could help guide future vaccine approvals. We thereby looked to see what parameters pre-challenge might best predict the challenge outcomes. This analysis showed that serum neutralizing antibody titers pre-challenge had a high correlation with lung protection post-challenge, consistent with the fact that Covid-19 vaccines appear most effective at protecting against serious disease and death. While there was also a correlation between neutralizing antibody titers and day 3 virus titers in the nasal bulb, this was not as strong suggesting that some other immune mediator such as memory T cells may play a stronger role in mucosal protection seen with our SWE-adjuvated Spike vaccine.

We note that our study has a number of limitations, as time and resources did not allow larger group sizes or the challenge and transmission study to be repeated. Nevertheless, the immunogenicity data obtained for the vaccines were consistent in mice and hamsters, suggesting the results showing greater potency of the Spike protein over the RBD vaccine were reliable. Future planned studies will explore the ability of our Spike protein vaccine to protect against challenge with Delta variant, which will be important given the high prevalence of the Delta strain globally, and the increasing evidence that existing Covid-19 vaccines provide suboptimal protection against infections by Delta virus. While we cannot guarantee that hamsters model human SARS-CoV-2 virus transmission, they are currently the most suitable model for transmission studies and it will be useful to undertake further studies to better define the mechanism whereby our Spike protein vaccine was able to prevent nasal virus replication and transmission. In addition to future research to evaluate the protective efficacy of NARUVAXC19 vaccine against important SARS-CoV-2 variants including delta in hamsters, we also plan to evaluate protection by NARUVAX-C19 vaccine in the non-human primate model. 
A subunit vaccine based on a recombinant Spike protein extracellular domain provided complete protection of Syrian hamsters against infection by wildtype SARS-CoV-2 (D614G) virus and also blocked virus transmission to naïve contact animals. This protection correlated with high titers of neutralizing antibodies that were also able to cross-neutralize the delta variant virus. Given this promising data NARUVAX-C19 vaccine will now be evaluated in the non-human primate model, before advancing to human clinical trials.

\section{Materials and Methods}

\section{Viruses and cell culture}

The virus strain hCoV-19/Kazakhstan/KazNAU-NSCEDI481/2020 of wildtype SARS-

CoV-2 with D614G mutation in Spike protein was used. This virus was isolated at the Aikimbayev National Research Center for Especially Dangerous Infections (NSCEDI) in June 2020 from nasopharyngeal swab of a 45-year-old COVID-19 patient in Almaty, Kazakhstan (GISAID, \#EPI_ISL_514093). We also used the delta variant (B.1.617.2) of SARS-CoV-2 isolated in August 17, 2021 from nasopharyngeal swab of a COVID-19 patient in Zhanaozen, Kazakhstan. Viruses were grown in Vero E6 cells (Vero 76, clone E6, CRL-1586, ATCC) with DMEM medium plus $2 \%$ fetal bovine serum (FBS) and antibiotic-antimycotic (containing penicillin 10,000 $\mathrm{U}$, streptomycin $10 \mathrm{mg}$ and amphotericin B $25 \mu \mathrm{g}$; \#15240096, Gibco $^{\mathrm{TM}}$ ) at 37 ${ }^{\circ} \mathrm{C}$ and 5\% $\mathrm{CO} 2$ for 3 days. The challenge virus used was at the passage level 3 with an infectivity titer of 6.2-7.2 $\log _{10} \mathrm{TCID}_{50} / \mathrm{ml}$.

\section{Recombinant Spike protein}

The detailed methodology of obtaining Spike protein has been described previously [8]. Briefly, the spike protein was identified from the SARS-CoV-2 genomic sequence in NCBI (access number: NC 045512) [25]. The codon-optimized insect cell expression cassette was 
cloned into pFASTBac1 and baculovirus was generated according to standard Bac-to-Bac procedures. The recombinant baculovirus was multiplied in Sf9 cells until the third passage and then used to infect High Five ${ }^{\mathrm{TM}}$ cells to express the protein. After $72 \mathrm{~h}$ of infection, the cell culture supernatant was purified by centrifugation and the recombinant ECD spike protein was purified on a HisTrap Excel column using an AKTA chromatography system, concentrated by ultrafiltration and replaced with PBS, sterilized by filtration. The sequence of the recombinant spike protein (rSpike) was confirmed by mass spectroscopy, SDS-PAGE gel, and Western blotting. Endotoxin was detected with the PyroGene ${ }^{\mathrm{TM}}$ Endotoxin Detection System (Cat. No. 50-658U, LONZA, Walkersville, MD, USA), and residual DNA content in the final vaccine product was determined with the Quant-iT ${ }^{\mathrm{TM}}$ PicoGreen $^{\mathrm{TM}}$ dsDNA Assay Kit (ThermoFisher, P7589) according to manufacturers' instructions.

\section{Vaccine formulation}

Commercial Spike RBD protein (receptor-binding domain) was obtained from ABP Biosciences. This RBD protein [Gln321-Ser591] was produced in HEK293 cells and had a stated purity $>95 \%$ as determined by SDS-PAGE and endotoxin $<1.0$ EU per $\mu$ g protein as determined by the LAL method.

Vaccine antigens (Spike or RBD) were formulated with Sepivac SWETM adjuvant (SWE;

Seppic, France) in a 50:50 ratio (by volume). SWE adjuvant with PBS was used as a negative control. All the preparations were sterile and contained less than 2.0 EU endotoxin per dose.

\section{Mice Vaccination and Immune Response Analysis}

Specific pathogen-free BALB/c female mice 4-6-week-old were obtained from the NSCEDI's breeding facility (Almaty, Kazakhstan). Animals were placed in ventilated cages with HEPA filters (Allentown, USA) for 7 days prior to the experiment for acclimatization. Mice ( $n=7-10 /$ group) were immunized intramuscularly (into the thigh area) in a volume of $100 \mu \mathrm{l}$ 
twice at 21-day intervals. At 21 days after prime and booster vaccination, blood samples were

421 collected from the orbital venous sinus and serum stored at $-20^{\circ} \mathrm{C}$ until used for antibody analysis (IgG n=7-10/group; IgG1/IgG2a, RBD-ACE2 blocking and Virus Neutralizing Ab n=7/group).

At 21 days after prime and booster vaccination, mice ( $\mathrm{n}=4$ /group) were euthanized (cervical dislocation under ketamine/xylazine anesthesia) and their spleens collected under aseptic conditions to assess $\mathrm{T}$-cell responses.

\section{Antibody analysis by ELISA}

Ninety-six well microplates (Nunc MaxiSorp, \#2297421, Invitrogen, USA) were coated with pre-titrated $0.5 \mu \mathrm{g} / \mathrm{ml}$ recombinant RBD or Spike protein on commercial buffer (ELISA Coating Buffer, \#B288159, BioLegend) overnight. Plates were blocked using ELISA Assay Diluent (\#421203, BioLegend) $200 \mu 1 /$ well and incubated under constant shaking (300-330 rpm on a PST-60HL thermal shaker, BIOSAN) for $1 \mathrm{~h}$ at room temperature. The plates were washed four times with ELISA Wash Buffer (\# 421601, BioLegend). Mouse serum samples were titrated two-fold from dilutions 1:125 to 1:32,000 (after prime vaccination) or 1:512000 (after booster vaccination), $100 \mu$ l samples were added from each dilution to the wells and incubated under constant shaking (300-330 rpm) for 1.5-2 $\mathrm{h}$ at room temperature. After washing (4x), secondary anti-mouse biotinylated IgG detection antibody (1:4000, \#B304057, BioLegend), IgG1, IgG2a (1:1000, \#B270354, B268020, BioLegend, $100 \mu \mathrm{l} /$ well) was added and the plates were incubated ( $1 \mathrm{~h}$ at room temperature with shaking). After additional washing (4x), plates were incubated with HRP Streptavidin (\# 405210, BioLegend, 1:1000, $100 \mu 1 /$ well) for 30 minutes at room temperature with shaking. Finally, plates were washed (5x) and added ready-to-use TMB substrate (\#N301, Thermo Fisher Scientific, $100 \mu 1 /$ well). The color reaction was stopped by adding a stop solution (\#B308260, BioLegend, $100 \mu 1 /$ well), and the optical density was analyzer (Awareness Tech). The cut-off value for determining the titer was calculated based on 
the average optical density (OD) values of the wells containing only the buffer (blank) + three standard deviation.

\section{Determination of RBD-ACE2 binding inhibition}

The SARS-CoV-2 Surrogate Virus Neutralization Test (sVNT) Kit (L00847; GenScript, Piscataway, USA) was used according to the manufacturer's instructions. Briefly, samples and controls were incubated with HRP-conjugated RBD (HRP-RBD) at $37^{\circ} \mathrm{C}$ for 30 min. Mixtures were added to a hACE2-coated capture plate and incubated at $37^{\circ} \mathrm{C}$ for $15 \mathrm{~min}$. The plates were then washed to remove the HRP-RBD neutralizing antibody complexes and allowing the unbound HRP-RBD and HRP-RBD non-neutralizing antibody complexes to bind to hACE2. TMB solution was added and incubated at room temperature for $15 \mathrm{~min}$, and the reaction was stopped with a stop solution. The OD was measured by spectrophotometry at $450 \mathrm{~nm}$. The percentage of inhibition of the sample was calculated as (1-Average OD of the sample/Average OD of the negative control) $\times 100 \%$. A sample with an inhibition percentage $<30 \%$ was considered "negative" and $\geq 30 \%$ "positive" for RBD-ACE2 binding antibodies. The following RBD-ACE2 binding antibody values were determined according to the level of inhibition: low (30-59\%), medium (60-89\%), high ( $\geq 90)$.

\section{Virus neutralizing antibody analysis in mice samples}

Serum samples were complement inactivated at $56^{\circ} \mathrm{C}$ for $30 \mathrm{~min}$ then serially two-fold diluted in medium (DMEM-2\% FCS-1\% Antibiotic-Antimycotic; in final dilutions of 1:20 to 1:2560) and incubated in duplicates at 1:1 ratio with 1000 TCID $_{50}$ of SARS-CoV-2 D614G mutant. After one hour incubation at room temperature, the serum-virus mixture was transferred to a 96-well plate (\#3596, Corning) covered with a monolayer (obtained by seeding with $5 \times 10^{4}$ cells per well and $24 \mathrm{~h}$ incubation, confluence was about 95\%) of Vero-E6 cell culture. After one hour, the inoculums were removed, fresh medium was added, and the plates were incubated at 
$37^{\circ} \mathrm{C}$ and 5\% CO2 for 3 days. The neutralizing antibody titer was the highest dilution of serum that inhibited the cytopathic effect in $100 \%$ of wells. The cytopathic effect was assessed visually using a MIB-R trinocular inverted biological microscope (LOMO-Microsystems, Russia) with a magnification of $\mathrm{x} 10$.

\section{Analysis of cytokines}

Mice spleens were mechanically pulverized into single cell suspension using a cell strainer (Falcon® $\left.{ }^{\circledR} 0 \mu \mathrm{m}\right)$. The pulverization procedure was performed on a disposable sterile Petri dish (\#840007, Piove di Sacco, Italy) with $10 \mathrm{ml}$ of 3\% fetal bovine serum (FBS, US Origin, \#VP1810311, Millipore Corp., Germany) in PBS. Erythrocytes were lysed with RBC lysis buffer (\#B333276, BioLegend). Splenocytes were cultured in a 5\% CO2 incubator (INCO 153, Memmert, Germany) at $37^{\circ} \mathrm{C}$ in 24-well flat-bottomed plates (\#04618024, Sigma-Aldrich, USA) at $1 \times 10^{6}$ cells/well ( $\left.1 \mathrm{ml}\right)$ in RPMI-1640 + GlutaMax medium (\#2242279, Gibco) with 20 mM HEPES (\#15630-080, Gibco), 10\% FBS (inactivated by heating) and 1\% AntibioticAntimycotic (\#15240096, Gibco ${ }^{\mathrm{TM}}$ ) in the presence of $5 \mu \mathrm{g}$ of recombinant RBD/Spike protein or without protein (control without stimulation). Concanavalin A (\#11028-71-0, InvivoGen) was used as a positive control or T-cell mitogen at a concentration of $50 \mu \mathrm{g} / \mathrm{ml}$. Cells were incubated for 72 hours, after which the supernatant was examined for cytokines IL-2 (\#B320273), IFN- $\gamma$ (\#B307222), IL-4 (\#B320413), IL-10 (\#B311304), IL-5 (\#B317463), IL-6 (\#B321215), IL-17A (\#B303513), TNF- $\alpha$ (\#B306271) using ELISA MAX ${ }^{\mathrm{TM}}$ Deluxe Set Mouse (BioLegend) kits, according to manufacturer instructions. The data were presented as the difference (Delta) in OD between samples with and without vaccine protein stimulation.

\section{Analysis of CD4+ and CD8+ T cell proliferation}

$\mathrm{T}$ cell proliferation assay was performed by incubating isolated splenocytes for 5 minutes in the dark on ice with $5 \mu \mathrm{M}$ CFSE (Carboxyfluorescein succinimidyl ester, eBioscienceTM, 
\#2298273, Invitrogen, USA), and immediately the staining was quenched with 3\% FBS. Cells were cultured at $10^{6}$ cells $/ \mathrm{ml}$ in 24 -well plates for 5 days at $37^{\circ} \mathrm{C}$ in $5 \% \mathrm{CO} 2$ with or without 5 $\mu \mathrm{g} / \mathrm{ml}$ of RBD or Spike protein. Phenotype of cells was determined by analysis of CD markersstained cells using Flow Cytometry. Briefly, cells were first incubated with TruStain FcX ${ }^{\mathrm{TM}}$ (anti-mouse CD16/32, to block nonspecific binding of immunoglobulin to Fc receptors) at a concentration of $0.5 \mu \mathrm{g} / 10^{6}$ cells for $5-10$ min on ice before immunostaining. The cells were then incubated with antibodies specific to surface markers for $30 \mathrm{~min}$ in the dark on ice. The following fluorochrome-labeled antibodies were used: R-PE anti-CD8a (\#2170194, Invitrogen, USA) at a concentration of $0.25 \mu \mathrm{g}$, violetFluorTM 450-anti-CD4 (\#ab241097, Abcam) at a concentration of $0.125 \mu \mathrm{g}$ per $100 \mu \mathrm{l}$ of splenocyte suspension. After incubation, cells were resuspended in Flow Cytometry Staining Buffer (eBioscience, \#2231157, Invitrogen, USA) up to $0.5 \mathrm{ml}$, stained with $0.25 \mu \mathrm{g}$ of 7-AAD solution, and incubated for 5-10 minutes in the dark (BioLegend Cat. No. 420403) to exclude dead cells. At least $5 \times 10^{5}$ cells were analyzed for each sample on an Attune ${ }^{\mathrm{TM}}$ NxT flow cytometer (Thermo Fisher Scientific, USA) using Attune NxT Software (Thermo Fisher Scientific, USA). T-cell population was analyzed in the lymphocyte gate isolated on FCS/SSC dot-plot. CD4+ and CD8+ T cell proliferation was calculated as the difference $(\Delta)$ in antigen stimulated and unstimulated samples to the total number of live proliferating (CFSE+) splenocytes and expressed as a percentage.

\section{Vaccination of Syrian hamsters and collection of blood samples}

Six- to eight-week-old male Syrian hamsters obtained from the NSCEDI's laboratory animal breeding facility were used. Animals were placed in ventilated cages with HEPA filters (Allentown, USA) for 7 days prior to the experiment for acclimatization. Hamsters were immunized with RBD and Spike-based vaccine formulations containing $5 \mu \mathrm{g} / \mathrm{dose}$ antigen and a control sample intramuscularly (into the thigh area) in a volume of $200 \mu 1$ twice at 21-day intervals. On day 21 after booster (n=6/group) vaccination, blood samples were collected from 
the hyoid venous plexus (under ketamine/xylazine anesthesia) and serum was stored at $-20^{\circ} \mathrm{C}$ until used in antibody analysis. For determining the virus neutralizing antibodies $1000 \mathrm{TCID}_{50}$ of wild-type (D614G) or delta variant of SARS-CoV-2 were used.

\section{Antibody analysis in hamster samples}

ELISA was performed as described above for the mouse samples. Except the hamster serum samples were titrated starting from dilution 1:125 to 1:256000. Secondary Goat Anti-Syrian Hamster IgG H\&L biotinylated antibody (1:4000, \#ab6891, Abcam, MA, USA) was used for IgG antibody detection. Determination of RBD-ACE2 blocking antibodies and virus neutralizing antibody titers were determined against SARS-CoV-2 wild-type with D614G mutant and delta variant viruses as described above. Serum samples from four hamsters previously infected with the wild-type SARS-CoV-2 virus with a D614G mutation in the spike protein were used for comparison. Serum samples from previously infected hamsters were taken 21 days after challenge.

\section{Assessing the vaccine protective efficacy in hamsters}

On day 21 after booster injection, hamsters were infected with WT SARS-CoV-2 at a dose of $1 \times 10^{4} \mathrm{TCID}_{50}$ intranasally under intraperitoneal ketamine $(100 \mathrm{mg} / \mathrm{kg})$ and xylazine $(10$ $\mathrm{mg} / \mathrm{kg}$ ) anesthesia. Animals were observed for 7 days daily twice after challenge and body weight recorded daily. On days 3 and 7 after infection, half of the animals (3/6) from each group were euthanized and collected nasal turbinate and lung samples. Three lobes of the right lung from each animal were fixed in 10\% formalin for histopathological examination. Two lobes of the left lung were homogenized in $1 \mathrm{ml}$ DMEM using a TissueLyser II instrument (QIAGEN) at 300 vibrations/min for 60 seconds, supernatant collected after centrifugation (5000 g for 15 min at $4^{\circ} \mathrm{C}$ ) was stored at $-70^{\circ} \mathrm{C}$ for detection of viral RNA and infectious viral titer. 


\section{Virus transmission analysis in hamsters}

In all the vaccinated groups of hamsters, on the second day after challenge, two naive SARS-CoV-2 hamsters were introduced. Two sentinels was left in contact with the infected animals for just one day and then removed and housed alone for a further 4 days before sacrifice whereas. Both the in contact animals were euthanized to assess the viral load in the nasal turbinates and lungs by RT-PCR and cell culture method. The weight of the animals was also determined within 5 days after replanting. Pathological changes in the lungs were evaluated by histology. Before co-mingling the naïve animals, oropharyngeal swabs collected from all the experimental challenged hamsters on day 2 after infection were assessed for the virus load which likely gets released to in contact animals.

\section{Real-time reverse transcriptional polymer-chain reaction}

Quantification of viral RNA in the samples was performed using a one-step Real-time RT-PCR. Tissue homogenate samples were used to isolate viral RNA using the QIAamp Viral RNA Mini Kit (Qiagen, Hilden, Germany) according to the manufacturer's instructions. RNA was eluted in $50 \mu \mathrm{l}$ of elution buffer and used for detection with a commercial real-time RT-PCR kit (NSCEDI) according to the manufacturer's instructions. The following primer pairs targeting to the N gene of the SARS-CoV-2 virus were used: F 5' - GGGGAACTTCTCCTGCTAGAAT; R 5' - CAGACATTTTGCTCTCAAGCTG. Amplification was performed as follows: $50^{\circ} \mathrm{C}$ for $10 \mathrm{~min}, 95^{\circ} \mathrm{C}$ for $2 \mathrm{~min}$, then 45 cycles consisting of $95^{\circ} \mathrm{C}$ for $15 \mathrm{~s}, 60^{\circ} \mathrm{C}$ for $30 \mathrm{~s}$ and a default melting curve in the RotorGene ${ }^{\circledR}$ machine (QIAGEN, USA). When the Ct values (cycles) on the FAM/Green and JOE/Yellow channels were $\geq 40$, the samples were considered negative for SARS-CoV-2.

\section{Detection of infectious titer load}


576 Tissue Culture Infectious Dose assay $\left(\right.$ TCID $\left._{50}\right)$. The tissue homogenates were diluted 10-fold in

577

medium (DMEM-2\% FCS-1\% Antibiotic-Antimycotic) and transferred in quadruplicates to 96well plates containing confluent Vero-E6 cells, incubated at $37^{\circ} \mathrm{C}$ and $5 \% \mathrm{CO} 2$ for 5 days.

Titration results were counted visually by microscopic examination of the cell monolayer for characteristic cytopathogenic effects (rounding and detachment of cells from the monolayer).

Virus titer was calculated according to the method of Reed and Mench and expressed in $\log _{10}$ $\mathrm{TCID}_{50} / 0.2 \mathrm{ml}$

\section{Histological analysis of hamster lungs}

Hamster lungs were fixed in $10 \%$ neutral buffer formaldehyde after excision, washed in water and then subjected to treatment with 4 portions of isopropyl $100 \%$ alcohol and 2 portions of xylene. The material was then impregnated in four portions of paraffin and blocks were casted. The histological blocks were sectioned ( $5 \mu \mathrm{m}$ thick) using a microprocessor-controlled microtome MZP-01 (KB Technom, Russia). The sections were dewaxed in 2 portions of xylene and 3 portions of ethyl alcohol with decreasing concentration $\left(96^{\circ}, 80^{\circ}, 70^{\circ}\right)$, and then stained with Hematoxylin (\#05-002, BioVitrum, Russia) - Eosin (\#C0362, DiaPath, Italy). This was followed by clarification in ascending ethyl alcohols $\left(70^{\circ}, 80^{\circ}, 96^{\circ}\right)$ and two portions of xylene. The sections were covered with coverslips using Bio Mount synthetic medium (\#2813, Bio Optica, Italy). The preparations were studied using an Mshot microscope (China), model MF52N. Photographs were taken at x40 magnification using an Mshot MS23 camera attachment (China) in the MShot Image Analysis System program (China). A magnification of x1000 was achieved with an oil immersion lens, and a standardized scale was used for calibration. All the measurements were made in $\mu \mathrm{m}$. Lung microscopic examination was performed according to classical canons accepted for parenchymatous organs, and the narrative was constructed according to the description of pathological conditions caused by SARS-CoV and SARS-CoV-2 
601 [26, 27]. Each slide was quantified based on the severity of histologic changes, including

602 interstitial pneumonia, alveolitis, bronchiolitis, alveolar destruction, interstitial infiltration,

603 pulmonary hemorrhage, and peribronchiolar inflammation. Scoring of pathological changes in

604 the lung sections: 4 points $=$ extremely severe; 3 points $=$ severe $; 2$ points $=$ moderate $; 1$ point $=$

605 mild; 0 point $=$ no changes [28].

606

607 Biosafety and Bioethics

608

All the work with the SARS-CoV-2 and animal experiments with virus were conducted

in NSCEDI's BSL-3 and ABSL-3 laboratories, wherein the international standard ISO

610

35001:2019 "Biorisk management for laboratories and other related organizations" was followed.

611

Laboratory animals were kept in individually ventilated cages (Tecniplast, Italy \& Allentown,

US) under a 12/12 light regime. The present study was conducted in accordance with national

and international laws and guidelines for handling of laboratory animals. The protocol was approved by the Institutional Committee on the Keeping and Use of Laboratory Animals of the NSCEI, Protocol No. 4 dated September 22, 2020.

616

\section{Statistical analysis}

The GraphPad Prism version 9.0.0 software program (San Diego, CA, USA) was used for statistical analysis of data. Differences in antibody titers, cytokine production, T-cell proliferation, weight loss, viral load, and pathological changes in the lungs between animal groups were assessed using Tukey's multiple comparison test, Š́íák's multiple comparison test or Dunnett's multiple comparison test. The detection limit of the virus titer was $0.7 \log _{10}$

$623 \mathrm{TCID}_{50} / 0.2 \mathrm{~mL}$, but for statistical analysis used that as $0.5 \log _{10} \mathrm{TCID}_{50} / 0.2 \mathrm{~mL}$. The detection limit of IgG titers and its isotypes was $7.0 \log _{2}$; neutralizing antibodies $3.0 \log _{2}$. Geometric mean titers (GMT) with 95\% confidence interval were calculated for all types of antibody data. The effect of different types of antibodies on vaccine protectiveness indicators such as weight 
dynamics, viral load in respiratory organs, and the level of pathological changes in the lungs was assessed using the multivariable Pearson correlation method. For all comparisons, $\mathrm{P}<0.05$ was considered statically significant.

\section{Conflict of interest statement}

NP and LL are affiliated with Vaxine Pty Ltd which holds the rights to COVAX-19 vaccine. None of the other authors has any financial or personal interest with any organization that could inappropriately influence or bias the research activity presented in this manuscript.

\section{Acknowledgements}

The authors thank Sandybaev N.T., Strochkov V.M., and Belousov V., for sequencing the SARS-CoV-2 viruses used in this study. Rysbekova A.K., Esimseit D.T, Abdeliev B.Z. for help in PCR analysis for SARS-CoV-2. Turegeldieva D.A., Zhambyrbaeva L.S., and Sarmantaeva K.B., for care and maintenance of laboratory animals. This research was supported by the Kazakh National Agrarian Research University and partially by the grant AP09259609 funded by the Science Committee of the Ministry of Education and Science of the Republic of Kazakhstan. Development of the recombinant spike protein was supported by National Institute of Allergy and Infectious Diseases of the National Institutes of Health under Contracts HHSN272201400053C and HHSN272201800024C.

\section{Author Contributions}

Conceptualization: KaissarT, NP

Data curation: KairatT

Formal analysis: KaissarT, NP

Funding acquisition: KaissarT, TlektesY, ToktasynY

Investigation: KairatT, NT, MB, GF, LL,

Methodology: KaissarT 
Resources: TlektesY, ToktasynY, LL

Software: KaissarT

Supervision: KaissarT

Validation: KairatT

Visualization: KaissarT, NP, GJR

Writing \pm original draft: KaissarT

Writing \pm review \& editing: KaissarT, NP, GJR, LL

\section{Data availability}

All data supporting the experimental findings of this study are available within the manuscript and are available from the corresponding author upon request.

\section{References}

1. World Health Organization. Coronavirus disease (COVID-19) pandemic. 2021. [accessed 2021 Aug 03]. https://www.who.int/emergencies/diseases/novel-coronavirus-2019.

2. Planas D, Veyer D, Baidaliuk A, Staropoli I, Guivel-Benhassine F, Rajah MM, Planchais C, Porrot F, Robillard N, Puech J, Prot M, Gallais F, Gantner P, Velay A, Le Guen J, Kassis-Chikhani N, Edriss D, Belec L, Seve A, Courtellemont L, Péré H, Hocqueloux L, FafiKremer S, Prazuck T, Mouquet H, Bruel T, Simon-Lorière E, Rey FA, Schwartz O. Reduced sensitivity of SARS-CoV-2 variant Delta to antibody neutralization. Nature. 2021 Jul 8. doi: 10.1038/s41586-021-03777-9. Epub ahead of print. PMID: 34237773.

3. Weisblum Y, Schmidt F, Zhang F, DaSilva J, Poston D, Lorenzi JC, Muecksch F, Rutkowska M, Hoffmann HH, Michailidis E, Gaebler C, Agudelo M, Cho A, Wang Z, Gazumyan A, Cipolla M, Luchsinger L, Hillyer CD, Caskey M, Robbiani DF, Rice CM, Nussenzweig MC, Hatziioannou T, Bieniasz PD. Escape from neutralizing antibodies by SARSCoV-2 spike protein variants. Elife. 2020 Oct 28;9:e61312. doi: 10.7554/eLife.61312. PMID: 33112236 ; PMCID: PMC7723407.

4. World Health Organization. COVID-19 vaccine tracker and landscape. [accessed 2021 Aug 03]. https://www.who.int/publications/m/item/draft-landscape-of-covid-19-candidatevaccines

5. Hannah Ritchie, Esteban Ortiz-Ospina, Diana Beltekian, Edouard Mathieu, Joe Hasell, Bobbie Macdonald, Charlie Giattino, Cameron Appel, Lucas Rodés-Guirao and Max Roser (2020) - "Coronavirus Pandemic (COVID-19)". Published online at OurWorldInData.org. Retrieved from: 'https://ourworldindata.org/coronavirus' [Online Resource]

6. Calina D, Docea AO, Petrakis D, Egorov AM, Ishmukhametov AA, Gabibov AG, Shtilman MI, Kostoff R, Carvalho F, Vinceti M, Spandidos DA, Tsatsakis A. Towards effective COVID-19 vaccines: Updates, perspectives and challenges (Review). Int J Mol Med. 2020 Jul;46(1):3-16. doi: 10.3892/ijmm.2020.4596 
7. Pollard, A. J. \& Bijker, E. M. A guide to vaccinology: from basic principles to new developments. Nat. Rev. Immunol. 21, 83-100 (2021).

8. Li L, Honda-Okubo Y, Huang Y, Jang H, Carlock MA, Baldwin J, Piplani S, BebinBlackwell AG, Forgacs D, Sakamoto K, Stella A, Turville S, Chataway T, Colella A, Triccas J, Ross TM, Petrovsky N. Immunisation of ferrets and mice with recombinant SARS-CoV-2 spike protein formulated with Advax-SM adjuvant protects against COVID-19 infection. Vaccine. 2021 Aug 3:S0264-410X(21)00992-0. doi: 10.1016/j.vaccine.2021.07.087.

9. Petrovsky N, Aguilar JC. Vaccine adjuvants: current state and future trends. Immunol Cell Biol. 2004 Oct;82(5):488-96. doi: 10.1111/j.0818-9641.2004.01272.x.

10. Wang Q, Zhang Y, Wu L, Niu S, Song C, Zhang Z, Lu G, Qiao C, Hu Y, Yuen KY, Wang Q, Zhou H, Yan J, Qi J. Structural and Functional Basis of SARS-CoV-2 Entry by Using Human ACE2. Cell. 2020 May 14;181(4):894-904.e9. doi: 10.1016/j.cell.2020.03.045.

11. Dalvie NC, Rodriguez-Aponte SA, Hartwell BL, Tostanoski LH, Biedermann AM, Crowell LE, Kaur K, Kumru O, Carter L, Yu J, Chang A, McMahan K, Courant T, Lebas C, Lemnios AA, Rodrigues KA, Silva M, Johnston RS, Naranjo CA, Tracey MK, Brady JR, Whittaker CA, Yun D, Kar S, Porto M, Lok M, Andersen H, Lewis MG, Love KR, Camp DL, Silverman JM, Kleanthous H, Joshi SB, Volkin DB, Dubois PM, Collin N, King NP, Barouch DH, Irvine DJ, Love JC. Engineered SARS-CoV-2 receptor binding domain improves immunogenicity in mice and elicits protective immunity in hamsters. bioRxiv [Preprint]. 2021 Mar 4:2021.03.03.433558. doi: 10.1101/2021.03.03.433558.

12. Brian D. Quinlan, Huihui Mou, Lizhou Zhang, Yan Guo, Wenhui He, Amrita Ojha, Mark S. Parcells, Guangxiang Luo, Wenhui Li, Guocai Zhong, Hyeryun Choe, Michael Farzan. The SARS-CoV-2 receptor-binding domain elicits a potent neutralizing response without antibody-dependent enhancement. bioRxiv 2020.04.10.036418; https://doi.org/10.1101/2020.04.10.036418

13. Yang S, Li Y, Dai L, Wang J, He P, Li C, Fang X, Wang C, Zhao X, Huang E, Wu C, Zhong Z, Wang F, Duan X, Tian S, Wu L, Liu Y, Luo Y, Chen Z, Li F, Li J, Yu X, Ren H, Liu L, Meng S, Yan J, Hu Z, Gao L, Gao GF. Safety and immunogenicity of a recombinant tandemrepeat dimeric RBD-based protein subunit vaccine (ZF2001) against COVID-19 in adults: two randomised, double-blind, placebo-controlled, phase 1 and 2 trials. Lancet Infect Dis. 2021 Aug;21(8):1107-1119. doi: 10.1016/S1473-3099(21)00127-4.

14. Vabret N, Britton GJ, Gruber C, Hegde S, Kim J, Kuksin M, Levantovsky R, Malle L, Moreira A, Park MD, Pia L, Risson E, Saffern M, Salomé B, Esai Selvan M, Spindler MP, Tan J, van der Heide V, Gregory JK, Alexandropoulos K, Bhardwaj N, Brown BD, Greenbaum B, Gümüş ZH, Homann D, Horowitz A, Kamphorst AO, Curotto de Lafaille MA, Mehandru S, Merad M, Samstein RM; Sinai Immunology Review Project. Immunology of COVID-19: Current State of the Science. Immunity. 2020 Jun 16;52(6):910-941. doi: 10.1016/j.immuni.2020.05.002.

15. Weiskopf D, Schmitz KS, Raadsen MP, Grifoni A, Okba NMA, Endeman H, van den Akker JPC, Molenkamp R, Koopmans MPG, van Gorp ECM, Haagmans BL, de Swart RL, Sette A, de Vries RD. Phenotype and kinetics of SARS-CoV-2-specific T cells in COVID-19 patients with acute respiratory distress syndrome. Sci Immunol. 2020 Jun 26;5(48):eabd2071. doi: 10.1126/sciimmunol.abd2071.

16. Abdelnabi R, Boudewijns R, Foo CS, Seldeslachts L, Sanchez-Felipe L, Zhang X, Delang L, Maes P, Kaptein SJF, Weynand B, Vande Velde G, Neyts J, Dallmeier K.Comparing infectivity and virulence of emerging SARS-CoV-2 variants in Syrian hamsters. EBioMedicine. 2021; 68:103403. doi: 10.1016/j.ebiom.2021.103403 
17. Plante JA, Liu Y, Liu J, Xia H, Johnson BA, Lokugamage KG, Zhang X, Muruato AE, Zou J, Fontes-Garfias CR, Mirchandani D, Scharton D, Bilello JP, Ku Z, An Z, Kalveram B, Freiberg AN, Menachery VD, Xie X, Plante KS, Weaver SC, Shi PY. Spike mutation D614G alters SARS-CoV-2 fitness. Nature. 2021 Apr;592(7852):116-121. doi: 10.1038/s41586-0202895-3.

18. Bricker TL, Darling TL, Hassan AO, Harastani HH, Soung A, Jiang X, Dai YN, Zhao H, Adams LJ, Holtzman MJ, Bailey AL, Case JB, Fremont DH, Klein R, Diamond MS, Boon ACM. A single intranasal or intramuscular immunization with chimpanzee adenovirus-vectored SARS-CoV-2 vaccine protects against pneumonia in hamsters. Cell Rep. $2021 \mathrm{Jul}$ 20;36(3):109400. doi: 10.1016/j.celrep.2021.109400.

19. Tostanoski LH, Wegmann F, Martinot AJ, Loos C, McMahan K, Mercado NB, Yu J, Chan CN, Bondoc S, Starke CE, Nekorchuk M, Busman-Sahay K, Piedra-Mora C, Wrijil LM, Ducat S, Custers J, Atyeo C, Fischinger S, Burke JS, Feldman J, Hauser BM, Caradonna TM, Bondzie EA, Dagotto G, Gebre MS, Jacob-Dolan C, Lin Z, Mahrokhian SH, Nampanya F, Nityanandam R, Pessaint L, Porto M, Ali V, Benetiene D, Tevi K, Andersen H, Lewis MG, Schmidt AG, Lauffenburger DA, Alter G, Estes JD, Schuitemaker H, Zahn R, Barouch DH. Ad26 vaccine protects against SARS-CoV-2 severe clinical disease in hamsters. Nat Med. 2020 Nov;26(11):1694-1700. doi: 10.1038/s41591-020-1070-6

20. Kalnin KV, Plitnik T, Kishko M, Zhang J, Zhang D, Beauvais A, Anosova NG, Tibbitts T, DiNapoli J, Ulinski G, Piepenhagen P, Cummings SM, Bangari DS, Ryan S, Huang PD, Huleatt J, Vincent D, Fries K, Karve S, Goldman R, Gopani H, Dias A, Tran K, Zacharia M, Gu X, Boeglin L, Abysalh J, Vargas J, Beaulieu A, Shah M, Jeannotte T, Gillis K, Chivukula S, Swearingen R, Landolfi V, Fu TM, DeRosa F, Casimiro D. Immunogenicity and efficacy of mRNA COVID-19 vaccine MRT5500 in preclinical animal models. NPJ Vaccines. 2021 Apr 19;6(1):61. doi: 10.1038/s41541-021-00324-5.

21. van Doremalen N, Lambe T, Spencer A, Belij-Rammerstorfer S, Purushotham JN, Port JR, Avanzato VA, Bushmaker T, Flaxman A, Ulaszewska M, Feldmann F, Allen ER, Sharpe H, Schulz J, Holbrook M, Okumura A, Meade-White K, Pérez-Pérez L, Edwards NJ, Wright D, Bissett C, Gilbride C, Williamson BN, Rosenke R, Long D, Ishwarbhai A, Kailath R, Rose L, Morris S, Powers C, Lovaglio J, Hanley PW, Scott D, Saturday G, de Wit E, Gilbert SC, Munster VJ. ChAdOx1 nCoV-19 vaccine prevents SARS-CoV-2 pneumonia in rhesus macaques. Nature. 2020 Oct;586(7830):578-582. doi: 10.1038/s41586-020-2608-y.

22. Watterson D, Wijesundara DK, Modhiran N, Mordant FL, Li Z, Avumegah MS, McMillan CL, Lackenby J, Guilfoyle K, van Amerongen G, Stittelaar K, Cheung ST, Bibby S, Daleris M, Hoger K, Gillard M, Radunz E, Jones ML, Hughes K, Hughes B, Goh J, Edwards D, Scoble J, Pearce L, Kowalczyk L, Phan T, La M, Lu L, Pham T, Zhou Q, Brockman DA, Morgan SJ, Lau C, Tran MH, Tapley P, Villalón-Letelier F, Barnes J, Young A, Jaberolansar N, Scott CA, Isaacs A, Amarilla AA, Khromykh AA, van den Brand JM, Reading PC, Ranasinghe C, Subbarao K, Munro TP, Young PR, Chappell KJ. Preclinical development of a molecular clamp-stabilised subunit vaccine for severe acute respiratory syndrome coronavirus 2 . Clin Transl Immunology. 2021 Apr 5;10(4):e1269. doi: 10.1002/cti2.1269

23. Wu Y, Huang X, Yuan L, Wang S, Zhang Y, Xiong H, Chen R, Ma J, Qi R, Nie M, Xu J, Zhang Z, Chen L, Wei M, Zhou M, Cai M, Shi Y, Zhang L, Yu H, Hong J, Wang Z, Hong Y, Yue M, Li Z, Chen D, Zheng Q, Li S, Chen Y, Cheng T, Zhang J, Zhang T, Zhu H, Zhao Q, Yuan Q, Guan Y, Xia N. A recombinant spike protein subunit vaccine confers protective immunity against SARS-CoV-2 infection and transmission in hamsters. Sci Transl Med. 2021 Aug 11;13(606):eabg1143. doi: 10.1126/scitranslmed.abg1143. Epub 2021 Jul 20. PMID: 34285130 . 
24. Osterrieder N, Bertzbach LD, Dietert K, Abdelgawad A, Vladimirova D, Kunec D, Hoffmann D, Beer M, Gruber AD, Trimpert J. Age-Dependent Progression of SARS-CoV-2 Infection in Syrian Hamsters. Viruses. 2020 Jul 20;12(7):779. doi: 10.3390/v12070779.

25. Wu F, Zhao S, Yu B, Chen YM, Wang W, Song ZG, Hu Y, Tao ZW, Tian JH, Pei YY, Yuan ML, Zhang YL, Dai FH, Liu Y, Wang QM, Zheng JJ, Xu L, Holmes EC, Zhang YZ. A new coronavirus associated with human respiratory disease in China. Nature. 2020 Mar;579(7798):265-269. doi: 10.1038/s41586-020-2008-3.

26. Gruber AD, Osterrieder N, Bertzbach LD, Vladimirova D, Greuel S, Ihlow J, Horst D, Trimpert J, Dietert K. Standardization of Reporting Criteria for Lung Pathology in SARS-CoV2-infected Hamsters: What Matters? Am J Respir Cell Mol Biol. 2020 Dec;63(6):856-859.

27. Matute-Bello G, Downey G, Moore BB, Groshong SD, Matthay MA, Slutsky AS, Kuebler WM; Acute Lung Injury in Animals Study Group. An official American Thoracic Society workshop report: features and measurements of experimental acute lung injury in animals. Am J Respir Cell Mol Biol. 2011 May;44(5): 725-38.

28. Lu M, Dravid P, Zhang Y, Trivedi S, Li A, Harder O, Kc M, Chaiwatpongsakorn S, Zani A, Kenney A, Zeng C, Cai C, Ye C, Liang X, Shimamura M, Liu SL, Mejias A, Ramilo O, Boyaka PN, Qiu J, Martinez-Sobrido L, Yount JS, Peeples ME, Kapoor A, Niewiesk S, Li J. A safe and highly efficacious measles virus-based vaccine expressing SARS-CoV-2 stabilized prefusion spike. Proc Natl Acad Sci U S A. 2021 Mar 23;118(12):e2026153118. 